EPiC Series in Engineering
Volume 3, 2018, Pages 692-697
HIC 2018. 13th International
Conference on Hydroinformatics

\title{
An Approach for Urban Catchment Model Updating
}

\author{
Maria Clara Fava ${ }^{1,2 *}$, Maurizio Mazzoleni ${ }^{2}$, Narumi Abe ${ }^{1}$, Eduardo Mario \\ Mendiondo ${ }^{1}$ and Dimitri P. Solomatine ${ }^{2,3}$ \\ ${ }^{1}$ São Carlos School of Engineering - University of São Paulo, São Carlos, São Paulo, Brazil. \\ ${ }^{2}$ IWSG, IHE Delft Institute for Water Education, Westvest 7, 2611 AX Delft, the Netherlands. \\ ${ }^{3}$ Water Resources Section, Delft University of Technology, the Netherlands.
}

\begin{abstract}
Places with limited coverage of rainfall gauges could present the challenge of providing accurate predictions, especially in cases of urbanised areas with rapid responses to heavy rainfall events. Physically-based models can represent the physics and spatial distribution of rainfall events in urban watersheds. Data assimilation techniques have been widely used in hydraulic and hydrological models to update model states and provide a more reliable prediction. However, model updating in case of non-linear systems is considerably complex. In this study, we present an approach to update an urban model assimilating water level values. The preliminary results of this study show a significant improvement in the results of simulations when assimilating water level observation. The methodology is applied in the city of São Carlos, in Brazil, where the urban system is modelled using SWMM.
\end{abstract}

Keywords: Data assimilation; Distributed model; Flood modelling; Physically-based model; SWMM.

\section{Motivation}

There have been important advances in modelling urban hydrology with models capable of reproducing the temporal and spatial patterns of physical phenomena. However, many studies are required to better investigate the spatiotemporal dynamics of urban rainfall to improve short-term flood forecasting and water quality management (Fletcher, 2013). In addition, the increasing demand in complex hydrological and hydraulic problems associated with rapid urbanisation and agricultural

\footnotetext{
* Corresponding author: mclarafava@usp.br
} 
activities expansion requires developing more accurate models (El Hassan, 2013). Data assimilation (DA) techniques became widely used to improve hydrological predictions updating the model as response to real-time observations. Meanwhile, a recent study demonstrates that further studies are required for the operational application of data assimilation techniques (Restrepo, 2012).

\section{Problem Statement}

In the assimilation process, updates could be made in the inputs variables, parameters or states of the model (Liu, 2007). Most of the available physically based and hydrodynamic models are complex and time consuming. Even considering that the streamflow is lumped-conceptual in the sub-basins scale, the distributed-physical component that describes the hydrodynamics of flows solves partial differential equations that make it computationally demanding (Hansen, 2014). Taking this into account, new DA approaches with the aiming to update states of physically based models in faster ways are demanded. For this reason, the goal of this study is present a DA methodology that updates the input variable of a model based on the error between field water level data and simulated water level. We applied the proposed method in the urban basin of São Carlos, Brazil using the Storm Water Management Model (SWMM) from the U.S. Environmental Protection Agency (US EPA) (Rossman, 2010).

\section{Methodology}

EPA-SWMM is a rainfall-runoff model capable of performing single event or long-term simulations of runoff in urban areas through hydrological and hydraulic modules. The hydrological module simulates the sub-catchments behaviour including an internal infiltration module. The runoff component is lumped and conceptual in the sub-catchment scale. Each sub-catchment defined by the user is divided into pervious and impervious portions. Each part is modelled as a nonlinear reservoir with a capacity given to the maximum depression storage. The hydraulic module calculates the streamflow in the rivers or channels, and the surface runoff that comes from the hydrological model on the watershed during rainfall events.

We model the urban basin of São Carlos (Monjolinho basin) considering 35 nodes and 15 sub-basins with drainage areas ranging from $0.011 \mathrm{~km}^{2}$ to $2.18 \mathrm{~km}^{2}$. The total area is $76.8 \mathrm{~km}^{2}$, and it has a population density of 194.53 inhabitants $/ \mathrm{km}^{2}$. The basin has an average altitude of 856 meters above sea level, and soil is considered highly permeable. In modelling, we opt for the infiltration model based on the SCS Curve Number. This method is an approach adapted for the curve number (CN) of the NRSS (National Resources Conservation Service) to estimate the runoff. The selected flow propagation model is the dynamic wave, and the model is rainfall driven. The input data come from four rain gauges distributed as shown in Figure 1. To make the spatial distribution of the rainfall, we use the Inverse distance weighting (IDW) method to interpolate data from gauge station and estimate the mean spatial value for each one of the fifteen sub-catchments using the distance of the centroid as a weight. 


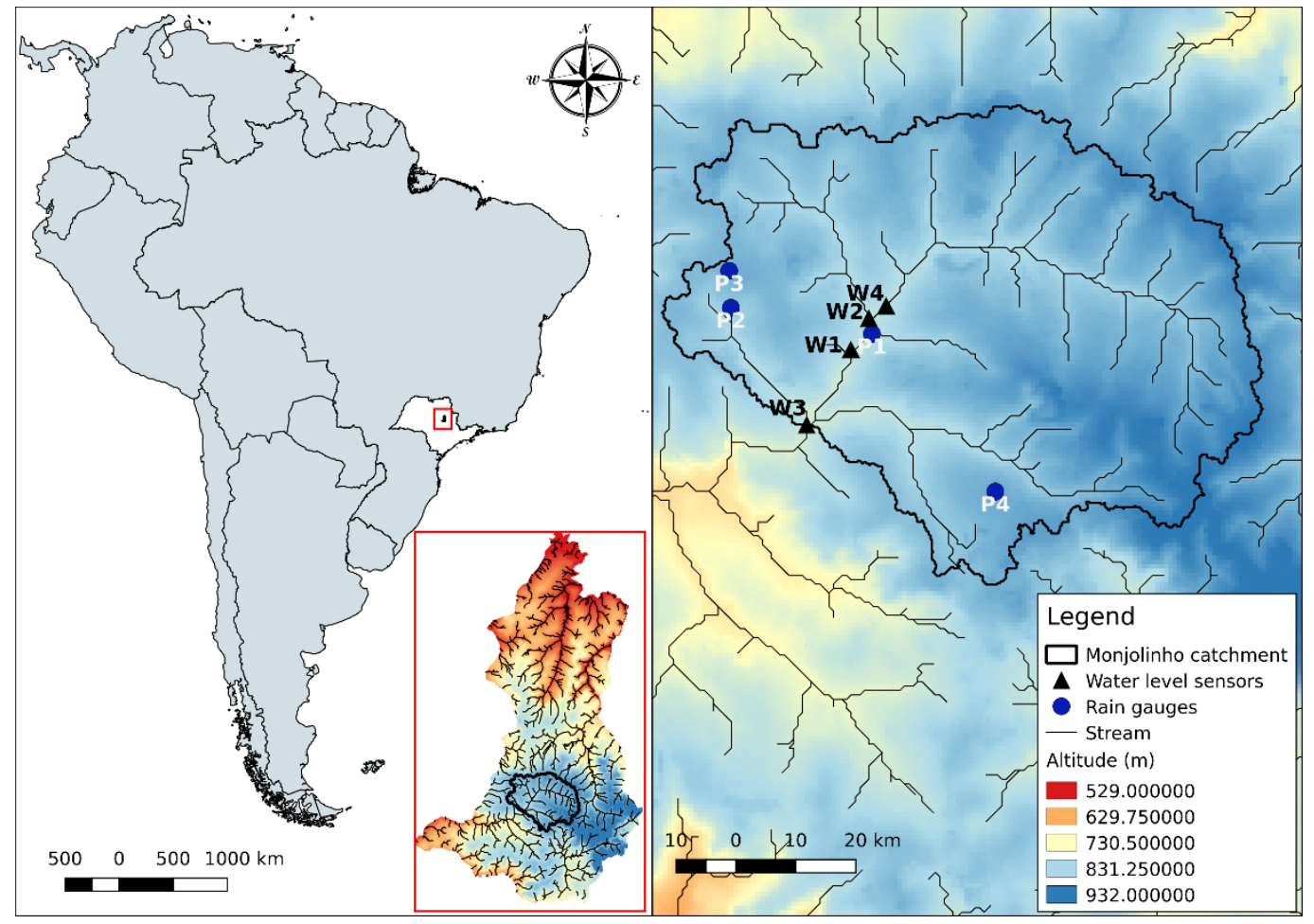

Figure 1- Urban basin model of São Carlos and monitoring points.

After modelling, we develop an automatic calibration tool for SWMM using genetic algorithms (GA). This tool is designed using Python 3.5, DEAP library for genetic algorithms (Fortin, 2012) and the library SWMM5 for SWMM calling interface (Pathirana, 2015). G.A details: two-point crossover, flip bit mutation algorithm and selection by tournament, $50 \%$ crossover probability and $20 \%$ mutation probability. The calibration tool uses data from four water level monitoring points (Figure 1) to optimise the model parameters. The objective function is to maximise the sum of Nash-Sutcliffe coefficient (NSE) for that locations. The following hydrological parameters are used for calibration: width and average slope ( $20 \%$ of variation allowed), the runoff curve number, a percentage of impervious area, manning's coefficient for pervious and impervious area, percent of impervious area with no depression storage, depth of depression storage on pervious and impervious area. For the hydraulic model, we calibrate the roughness. The sub-catchments and conduits were grouped according to the similarity in land use cover, and different range limits were assigned to each group. Thus, the calibration tool uses those range limits as search space. 13 rainfall events between November 2013 and April 2014 are used for calibration and validation. The events were chosen at random and divided into two sets: seven of them for calibration and six events for validation. The events were sort between pairs grouped by the similarity in average intensity rainfall. Model calibration resulted in an average NSE of 0.60 for calibration period and 0.67 for validation period.

In this study, we consider just one source of uncertainty, assuming that the error in the water level simulations performed by the model comes from the rainfall. From that assumption, we developed a model updating procedure that changes the inputs (rainfall) to reach better predictions when receiving water level field data. To perform the assimilation of field data values we propose an optimisation method based on the assimilation of water levels aiming the minimisation of deviation between the observed and simulated water level values. The method should optimise rainfall amounts that we will add or withdrawn in previous running of the model until the moment when receiving field data to reduce 
as much as possible de deviation between water level simulated and observed. Each sub-catchment has its rainfall data estimated by the IDW method, and its values are updated by the optimisation technique using a different factor for each one. We choose GA as a tool to search for the best solutions of values combination for the factors that will change rainfall.

\section{Results and discussion}

The proposed methodology is applied during an extreme event occurred on 11/04/2013 in São Carlos - SP. Water level observations are assimilated at three moments $14 \mathrm{~h} 00$ (beginning of the flood wave), $15 \mathrm{~h} 00$ (peak of the flood event) and $16 \mathrm{~h} 00$ (falling limb of the flood wave), respectively. Figure 2 shows the changes in the water level simulations when assimilating one information per time or all together. Overall, it is observed an improvement of model results. However, we can notice that assimilating the water level data at the beginning of the event does not influence model results. The observation assimilated at the peak of the flood tends to provide good improvement during the event but then overestimates the water level values during the falling limbs. The highest model performances are achieve assimilating all three water level information. The data obtained at $16 \mathrm{~h} 00$ helped to reduce the values after the peak as shown in Table 1- NSE comparing the water levels measured at the observation point and model simulations. Table 1.
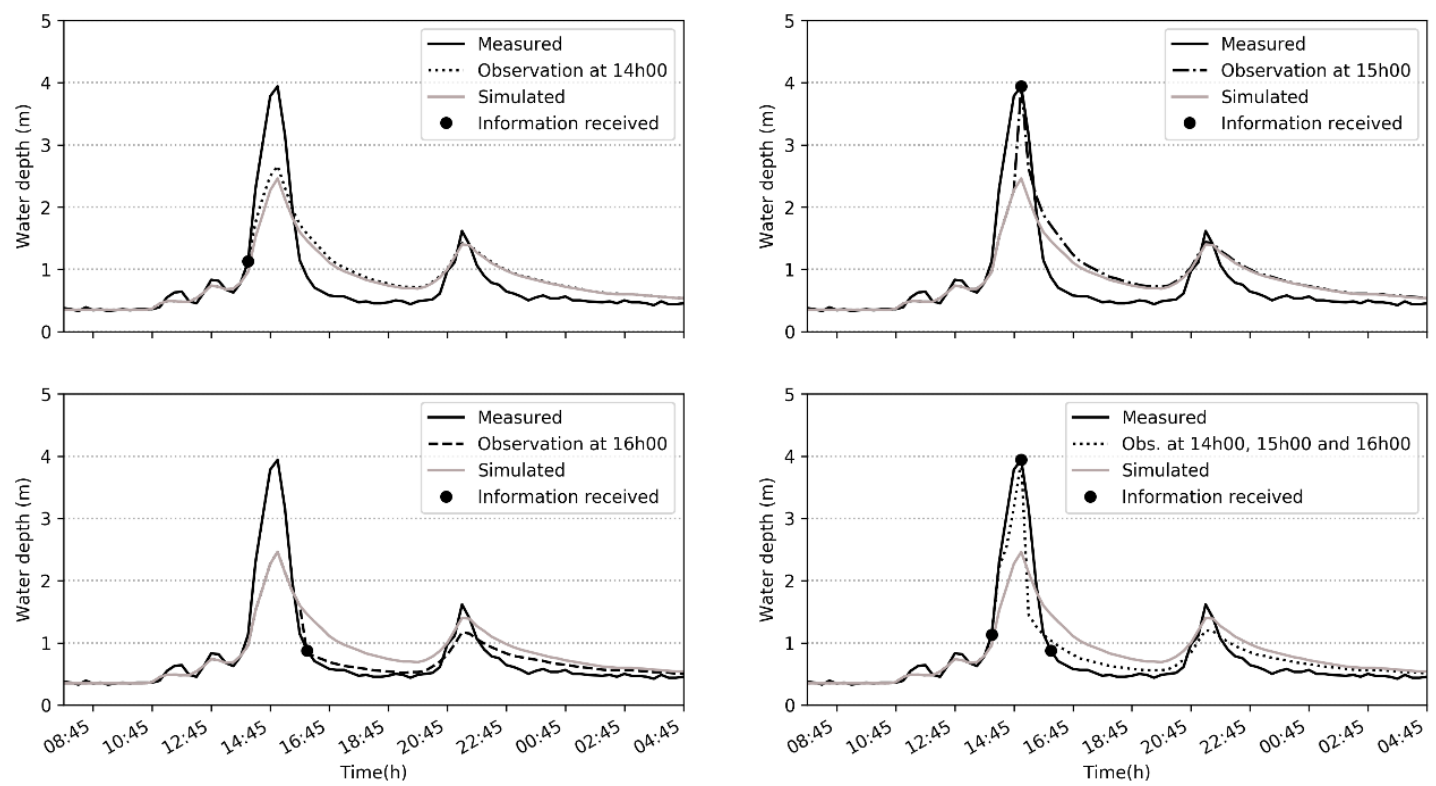

Figure 2- Response of the model to the quantitative variation of rainfall based on water level observations during a flood event in 11/04/2013 for the monitoring point W3. 
Table 1- NSE comparing the water levels measured at the observation point and model simulations.

\begin{tabular}{cc}
\hline Simulation & NSE \\
\hline No update & 0.711 \\
Assimilation at $14 \mathrm{~h} 00$ & 0.747 \\
Assimilation at $15 \mathrm{~h} 00$ & 0.734 \\
Assimilation at $16 \mathrm{~h} 00$ & 0.788 \\
Assimilation at 14h00, 15h00 and 16h00 & 0.889 \\
\hline
\end{tabular}

Figure 3 shows the box and whisker diagram generated by the rainfall event adjusted for the fifteen sub-catchments. That values of rainfall were obtained from the updating procedure with results showed in Figure 2. There is a large variation in the range for the first peak (14h30) as a result of the changes in the rainfall volume by the optimisation. The second peak deviation (21h00) is significantly lower because we don't assimilate any information after $16 \mathrm{~h}$. Therefore, the variation in the rainfall after this time only occurs due to the pre-existent differences in each sub-catchment rainfall data.

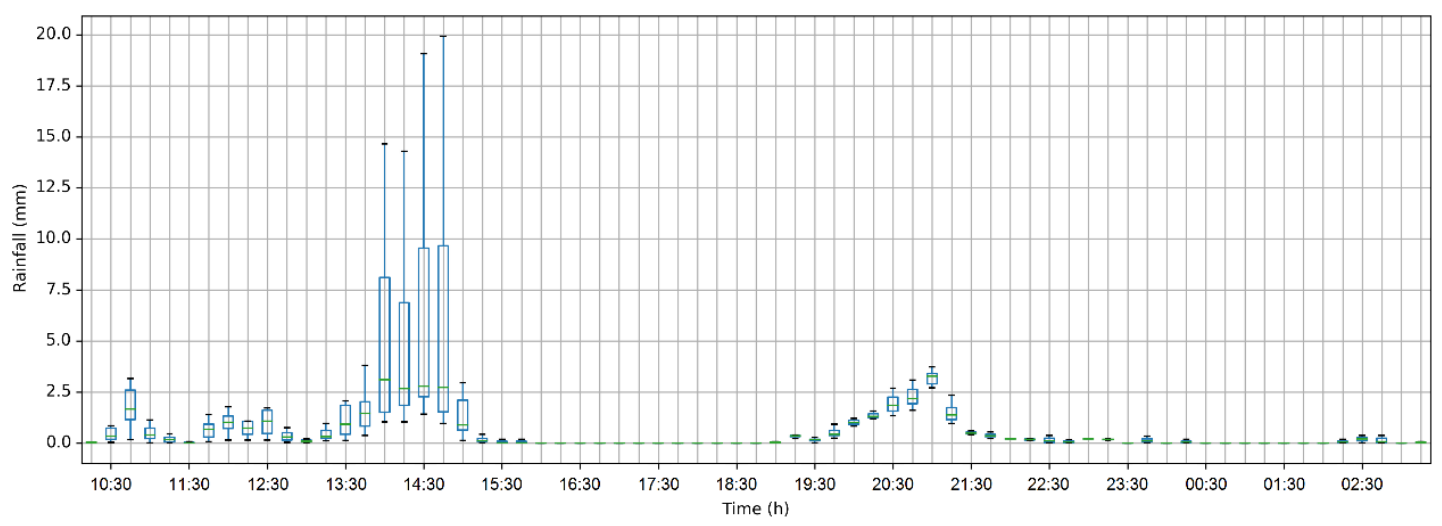

Figure 3- Boxplot of resulting data obtained for the rainfall of the fifteen sub-catchments.

\section{Conclusions}

The results of this research show that the approach of updating rainfall values assimilating water level data is capable of significantly improving the simulations making this approach a promising candidate to improve flood forecasting models. Additional, analyses are recommended to further improve the method. The authors recommend to explore the possibility to use sort of models faster than SWMM and other optimization schemes for future studies. Currently, we assimilate data coming from traditional water level sensors. However, this approach is not limited only to this type of data. For instance, we can also use data from citizen observatories as well.

\section{References}

El Hassan, A. A. (2013). Performance of a conceptual and physically based model in simulating the response of a semi-urbanized watershed in San Antonio, Texas. . Hydrological Processes, 27(24), 3394-3408. 
Fletcher, T. D. (2013). Understanding, management, and modelling of urban hydrology and its consequences for receiving waters: A state of the art. . Advances in Water Resources, 51, 261279.

Fortin, F. A. (2012). DEAP: Evolutionary algorithms made easy. Journal of Machine Learning Research, 2171-2175.

Hansen, L. S. (2014). low forecasting using deterministic updating of water levels in distributed hydrodynamic urban drainage models. . Water, 6(8), 2195-2211.

Liu, Y. \&. (2007). ncertainty in hydrologic modeling: Toward an integrated data assimilation framework. . Water Resources Research, 43(7).

Pathirana, A. (2015). SWMM5 python calling interface.

Restrepo, P. R. (2012). Advancing data assimilation in operational hydrologic forecasting: Progresses, challenges, and emerging opportunities. . Hydrology and Earth System Sciences, 16(10).

Rossman, L. A. (2010). Storm water management model user's manual, version 5.0. National Risk Management Research Laboratory, Office of Research and Development, US EPA. 